\title{
Cerebrospinal Fluid Tau in Frontotemporal Lobar Degeneration: Clinical, Neuroimaging, and Prognostic Correlates
}

\author{
Barbara Borroni ${ }^{\mathrm{a}, *}$, Carlo Cerini ${ }^{\mathrm{a}}$, Silvana Archetti ${ }^{\mathrm{b}}$, Enrico Premi $^{\mathrm{a}}$, Maura Cosseddu ${ }^{\mathrm{a}}$, \\ Maria Ferrari ${ }^{\mathrm{b}}$, Giuseppe Bellellic ${ }^{\mathrm{c}}$, Roberto Gasparotti ${ }^{\mathrm{d}}$, Luigi Caimi ${ }^{\mathrm{b}}$, Monica Di Luca ${ }^{\mathrm{e}}$ \\ and Alessandro Padovani ${ }^{\mathrm{a}}$ \\ ${ }^{\mathrm{a}}$ The Centre for Ageing Brain and Neurodegenerative Disorders, Neurology Unit, University of Brescia, \\ Brescia, Italy \\ ${ }^{\mathrm{b}}$ Laboratories of Biotechnology, Brescia Hospital, Brescia, Italy \\ ${ }^{\mathrm{c}}$ Department of Rehabilitation and Alzheimer's Evaluation Unit, Cremona and Geriatric Research Group, \\ Brescia, Italy \\ ${ }^{\mathrm{d}}$ Neuroradiology Unit, University of Brescia, Brescia, Italy \\ ${ }^{\mathrm{e}}$ The Centre of Excellence for Neurodegenerative Disorders, University of Milan, Milan, Italy
}

Accepted 6 October 2010

\begin{abstract}
Frontotemporal lobar degeneration (FTLD) refers to heterogeneous clinical and biological conditions. In FTLD, cerebrospinal fluid (CSF) tau levels have been reported highly variable. The aim of the present study was to evaluate whether CSF tau might be the hallmark of a distinct FTLD phenotype. Fifty-five FTLD patients, who underwent CSF analysis, were considered in the present study. In each patient, a wide standardized neuropsychological evaluation, and CSF tau, phospho-tau, and amyloid- $\beta(\mathrm{A} \beta)$ dosages were performed. Each patient was followed-up to five years, and outcomes carefully recorded. In a subgroup of patients $(n=24)$, magnetic resonance imaging scanning was performed, by using voxel-based morphometry, for grey matter investigation. The higher the CSF tau levels, the worse the neuropsychological and neuroimaging pattern, mainly characterized by greater language disturbances and left temporal grey matter loss. The same pattern, even if less significant, was associated with CSF phospho-tau, while CSF A $\beta$ levels did not play any influence on FTLD phenotype. FTLD patients with high CSF tau showed poor prognosis compared to those with low CSF tau $(p=0.031)$. In FTLD, CSF tau levels might be considered a marker of neurodegeneration, associated with a specific clinical and neuroimaging picture, and significantly related to poor outcome. Further studies aimed at defining the biological underpinnings of these findings are warranted.
\end{abstract}

Keywords: Biological marker, cerebrospinal fluid, frontotemporal dementia, frontotemporal lobar degeneration, tau

\section{INTRODUCTION}

Frontotemporal lobar degeneration (FTLD) is an heterogeneous clinical and biological disorder characterized by language deficits, impairment of executive functions, and behavioral disturbances [1]. FTLD is a more common form of dementia than previously recognized, with prevalence of up to 17 cases per

\footnotetext{
*Correspondence to: Barbara Borroni, MD, Clinica Neurologica, Università degli Studi di Brescia, Piazza Spedali Civili 1, Brescia, Italy. Tel.: +0039 0303995632; E-mail: bborroni@inwind.it.
}

100,000 inhabitants [2]. Despite clear-cut neuroimaging features, affecting frontal and temporal lobes [3], no diagnostic biological markers are available yet. Several studies have evaluated the usefulness of cerebrospinal fluid (CSF) total tau and phospho-tau levels in patients with FTLD, but with contrasting findings [4-8]. Indeed, while it has been widely demonstrated that CSF tau, phospho-tau, and amyloid- $\beta(\mathrm{A} \beta)$ markers are reliable tools to identify Alzheimer's disease in the preclinical stages [9-11], in FTLD, the results have been highly variable. Some studies have shown 
statistically increase of CSF tau, whereas others have shown unremarkable levels [4-8].

Different hypotheses for such a finding may be addressed. Firstly, CSF tau levels might be related to heterogeneous FTLD neuropathology, but no autopsy study investigating this issue has given definitive results. Second, CSF tau variability might be influenced by genetic variations within Microtuble Associated Protein Tau (MAPT), i.e., H1/H2 haplotype [12], or other genes that regulate Tau expression. Finally, tau in CSF might represent an aspecific marker of axonal damage, as increased levels are reported in many other conditions associated with neurodegeneration [13-17].

It has been widely demonstrated that neuroimaging is a promising tool to assess in vivo the potential role played by biological markers. Voxel-based morphometry (VBM) is a spatially-specific and unbiased method of analysis of magnetic resonance images reflecting the regional gray matter volume at a voxel scale, by anatomical definition of regional brain tissue damage/preservation [18,19].

In the present work, we examined the usefulness of CSF biomarkers, namely CSF tau and phosphotau, in defining a) distinct clinical and neuroimaging correlates in FTLD patients by a wide standardized neuropsychological assessment and VBM analysis, respectively, and b) in clarifying whether CSF biomarkers may reflect the degree of axonal damage and could predict the clinical outcome.

\section{METHODS}

\section{Subjects}

FTLD patients fulfilling current clinical criteria [1] were consecutively recruited from the Centre for Neurodegenerative Diseases, University of Brescia, Italy.

All subjects underwent a physical evaluation, a routine laboratory examination, a lumbar puncture for cerebrospinal fluid analyses, and a brain structural imaging study.

The diagnostic assessment involved a review of full medical history, a semi-structured neurological examination, and a complete mental status evaluation by at least two independent and experienced reviewers (B.B., G.B., A.P.). Only patients with full consensus agreement by the reviewers were enrolled. No patient carrying MAPT mutations was included, while three patients carried Progranulin mutations.

Demographic characteristics, the estimated age at onset of symptoms, and family history were carefully recorded. The age at onset of symptoms was based on a family report of the earliest persistently abnormal clinical feature in the domains of language, social function or personality change, executive functioning, or movement disorder. Patients considered to have a positive family history were those who had a first-degree relative with dementia, parkinsonism, or motor neuron disease. No patients belonging to the same family were included.

Each patient was followed-up over a 5-year period from the time of the study enrollment/diagnosis, and entry to nursing home or other long-term care facility (institutionalization) and death, and otherwise, was considered. This was determined by clinical periodic follow-up when possible, or by a telephone semistructured interview.

All participants were made fully aware about the aims of the research and informed consent was sought from all subjects. The work was conducted in accordance with local clinical research regulations and conformed to the Helsinki Declaration.

\section{Exclusion criteria}

Stringent exclusion criteria were applied as follows: a) cerebrovascular disorders, previous stroke, hydrocephalus, and intra-cranial mass documented by magnetic resonance imaging; b) a history of traumatic brain injury or another neurological disease; c) significant medical problems (e.g., poorly controlled diabetes or hypertension; cancer within the past 5 years; clinically significant hepatic, renal, cardiac, or pulmonary disorders); d) history of major depressive disorder, bipolar disorder, schizophrenia, substance abuse disorder, or mental retardation according to criteria of the DSM-IV; e) cerebrospinal fluid analyses not available.

\section{Cognitive, behavioral, and functional assessment at enrollment and at follow-up}

At first evaluation, each patient underwent a global cognitive function assessment according to a standardized battery, including the Mini-Mental State Examination (MMSE) [20] and FTD Clinical Dementia Rating (FTD-CDR) scale [21]. The neuropsychological assessment was carried out through the following tests: Story Recall Test [22], Raven Coloured Progressive Matrices [23], Rey Complex Figure Copy and Recall [24], Controlled Oral Word Association Test and Category Fluency [25], Digit Span [26], Token Test [27], Trail Making Test A and B [28], Clock's Drawing test [29], and De Renzi Imitation [30]. Instrumental Activities of Daily Living (IADL) and Basic Activities 
of Daily Living (BADL) were assessed as well. Motor impairment was evaluated using the motor subscale of Unified Parkinson Disease Rating Scale (UPDRS, part III). Behavioral and psychiatric disturbances were evaluated by Neuropsychiatry Inventory (NPI) [31], and Frontal Behavioral Inventory (FBI) [32].

The same standardized neuropsychological assessment was performed every year, when possible.

\section{Cerebrospinal fluid analyses}

CSF was obtained at the time of enrollment. Lumbar puncture was performed according to a standardized protocol, in the outpatient clinic, after fasting, from 9.30 a.m. to 10.30 a.m., after informed written consent had been obtained. CSF was collected in sterile polypropylene tubes and gently mixed to avoid gradient effects. Routine chemical measures were determined. The remaining CSF was centrifuged for $3 \mathrm{~min}$ at $3,000 \mathrm{rpm}$, and aliquots were stored at $-80^{\circ} \mathrm{C}$ or in liquid nitrogen for subsequent total-tau, phospho-tau and $\mathrm{A} \beta$ dosages. CSF concentrations were measured in duplicate by ELISA test (Innotest hTau Antigen kit and Innotest PHOSPHO-TAU 181P, Innogenetics, Ghent, Belgium). Interassay variability was less than $7 \%$.

According to the reference cut-off scores of our laboratory obtained on control subjects $(n=48)$ and Alzheimer's disease patients $(n=28), \mathrm{CSF}$ tau levels $>400 \mathrm{pg} / \mathrm{ml}, \mathrm{CSF}$ phospho-tau $>35 \mathrm{pg} / \mathrm{ml}$, and CSF $\mathrm{A} \beta<300 \mathrm{pg} / \mathrm{ml}$ are considered to be highly suggestive for Alzheimer's disease.

\section{MRI data acquisition}

Magnetic resonance imaging was performed on a 1.5 T Siemens (Simphony) scanner.

For VBM analysis, 3D MPRAGE T1-weighted images were acquired using the following parameters: $\mathrm{TE}=3.93 \mathrm{~ms}, \mathrm{TR}=2010 \mathrm{~ms}$, flip angle $=15$, and field of view $(\mathrm{FOV})=250 \mathrm{~mm}$. This yielded 176 contiguous 1-mm-thick slices. Both pre-processing and statistical analyses were implemented in the SPM2 software package (Wellcome Department of Imaging Neuroscience, London; http://www.fil.ion.ucl.ac.uk/spm) running on Matlab 6.5.1 (MathWorks, Natick, MA). Optimized-VBM analysis was performed according to Good et al. [33], and grey matter and total intracranial volume were considered, as previously published [3]. Age and gender were considered as nuisance variables. Correlation involved a regression of CSF markers on grey matter atrophy. Threshold was set at $p<0.001$, uncorrected, and the reliability of the statistical anal- ysis was confirmed using an extent threshold of 100 adjacent voxels.

\section{Statistical analyses}

Comparison between clinical subgroups was carried out using Pearson $\chi^{2}$, Student- $t$ test (unpaired), and Analysis of Variance (ANOVA), as appropriate. Spearman correlation analysis was performed to test the correlation between CSF markers and both demographic characteristics and neuropsychological tests.

Survival analyses were carried out by Cox proportional hazard models. Hazard ratios (HR) are given with their respective $95 \%$ confidence intervals (CI), while the significance level was established at $p<0.05$, two-sided. Kaplan Meier curves with log-rank posthoc testing were also performed. The analyses were conducted by SPSS software version 16 (SPSS Inc, Chicago, Ill).

\section{RESULTS}

\section{Subjects}

Sixty FTLD patients who underwent lumbar puncture for CSF analysis were consecutively enrolled and entered the study. From this sample, five patients with the diagnosis of FTLD but with low CSF A $\beta$ levels $(<300 \mathrm{pg} / \mathrm{ml})$, thus resembling Alzheimer's disease profile, were excluded.

The present study was conducted considering 55 FTLD. Demographic and clinical characteristics are shown in Table 1.

Overall, FTLD patients had a mean age of 62.8 (standard deviation, \pm 7.3 ), and $50.9 \%$ were female. The mean age at disease onset was 60.7 ( \pm 7.0$)$. FTLD patients were mild for global cognitive decline $(\mathrm{MMSE}=22.1 \pm 6.5)$. Behavioral variant of FTD (bvFTD) diagnosis was the most prevalent (81\%); semantic dementia (SD) and progressive non-fluent aphasia (PNFA) diagnoses were less frequent (19\%).

CSF profile in FTLD patients and in bvFTD, SD, PNFA subgroups is reported in Table 1. CSF markers showed a wide range of variability. No significant differences of CSF total tau, phospho-tau, or A $\beta$ levels among groups were found.

\section{CSF marker correlations with neuropsychological and behavioral assessment}

CSF tau, phospho-tau, and $A \beta$ levels did not correlate with demographic characteristics, such as age 
Table 1

Demographic and clinical characteristics of FTLD patients

\begin{tabular}{lccccc}
\hline Variable & FTLD (all) & bvFTD & SD & PNFA & $p^{*}$ \\
\hline$n(\%)$ & 55 & 45 & 4 & 6 & 0.730 \\
Age, years & $62.8 \pm 7.3$ & $63.1 \pm 7$ & $65.5 \pm 9.2$ & $58.8 \pm 8.4$ & 0.294 \\
Gender, F\% & $50.9 \%$ & $48.9 \%$ & $75 \%$ & $50 \%$ & 0.605 \\
Onset, years & $60.7 \pm 7.0$ & $60.9 \pm 6.6$ & $64 \pm 8.9$ & $57 \pm 7.8$ & 0.272 \\
Education, years & $7.1 \pm 3.4$ & $6.8 \pm 3.3$ & $11.5 \pm 4.3$ & $6.0 \pm 1.5$ & 0.023 \\
Family history, \% & $43.1 \%$ & $40.5 \%$ & $50.0 \%$ & $60.0 \%$ & 0.678 \\
MMSE & $22.1 \pm 6.5$ & $22.5 \pm 6.5$ & $19.3 \pm 7$ & $21 \pm 7.4$ & 0.652 \\
NPI & $16.4 \pm 13.5$ & $17.7 \pm 14.3$ & $16 \pm 4.0$ & $8.1 \pm 6.2$ & 0.279 \\
FBI, AB & $16.4 \pm 11.8$ & $17.5 \pm 12.6$ & $18.3 \pm 5.8$ & $8.8 \pm 2.8$ & 0.244 \\
CSF markers & & & & & \\
$\quad$ CSF tau (pg/ml) & $464.4 \pm 392.5$ & $472.6 \pm 413.5$ & $287.3 \pm 131.3$ & $521 \pm 346.1$ & 0.628 \\
CSF phosho-tau (pg/ml) & $88.7 \pm 94.5$ & $86.6 \pm 95.9$ & $53.6 \pm 23.0$ & $133.4 \pm 115.6$ & 0.438 \\
CSF A $\beta(\mathrm{pg} / \mathrm{ml})$ & $744.4 \pm 376.0$ & $711.0 \pm 329.0$ & $534.9 \pm 143.2$ & $1060.5 \pm 580.2$ & 0.057 \\
\hline
\end{tabular}

FTLD: Frontotemporal Lobar Degeneration; bvFTD: behavioral variant Frontotemporal Dementia; SD: Semantic Dementia; PNFA: Non-Fluent Progressive Aphasia; MMSE: Mini-Mental State Examination; NPI: Neuropsychiatry Inventory; FBI: Frontal Behavioral Inventory; CSF: cerebrospinal fluid.

* $p$-values refer to comparisons across groups, namely bvFTD, SD, PNFA.

(at CSF), age at symptom onset, gender, or education.

As reported in Table 2, correlation analysis between CSF markers, namely total tau, phospho-tau, and A $\beta$, and neuropsychological performances was carried out.

CSF tau was significantly associated with language comprehension, the higher the CSF tau the worse the Token test scores $(p=0.006)$. The same results, even if the $p$-values were less significant, were obtained when CSF phospho-tau levels were considered. Conversely, CSF A $\beta$ significantly correlated with verbal and nonverbal performances, lower $A \beta$ levels being associated with worse short story $(p=0.019)$ and recall of Rey figure $(p=0.044)$ scores, and with semantic fluency performances $(p=0.02)$.
No significant correlations of CSF markers and behavioral abnormalities were detected.

\section{CSF marker levels and brain atrophy}

To obtain evidence validating CSF marker correlation to neuropsychological profile, we correlated CSF data with grey matter in a subset of patients. Twentyfour patients out of 55 underwent a magnetic resonance imaging scan and VBM analysis. We evaluated the linear correlation between CSF markers and regional brain atrophy; the higher the CSF scores the greater the atrophy in specific brain regions.

As shown in Fig. 1 and in Table 3, when CSF total tau was considered, higher CSF tau levels were specifi-

Table 2

Correlations between CSF markers and neuropsychological assessment

\begin{tabular}{|c|c|c|c|c|c|c|}
\hline \multirow[t]{2}{*}{ Test } & \multicolumn{2}{|c|}{ CSF tau } & \multicolumn{2}{|c|}{ CSF phospho-tau } & \multicolumn{2}{|c|}{$\mathrm{CSF} A \beta$} \\
\hline & rho & $p$ & rho & $p$ & rho & $p$ \\
\hline Short story & -0.288 & 0.035 & -0.351 & 0.014 & 0.342 & 0.019 \\
\hline Rey figure, copy & -0.153 & 0.264 & -0.123 & 0.398 & 0.228 & 0.119 \\
\hline Rey figure, recall & -0.127 & 0.357 & -0.171 & 0.240 & 0.292 & 0.044 \\
\hline Semantic fluency & -0.244 & 0.073 & -0.267 & 0.063 & 0.325 & 0.024 \\
\hline Phonological fluency & -0.207 & 0.133 & -0.195 & 0.184 & 0.125 & 0.402 \\
\hline Digit span & -0.231 & 0.093 & -0.189 & 0.198 & 0.206 & 0.165 \\
\hline Raven Coloured Matrices & -0.016 & 0.909 & -0.047 & 0.748 & 0.201 & 0.170 \\
\hline Token test & -0.377 & 0.006 & -0.323 & 0.028 & 0.115 & 0.454 \\
\hline Trail Making test, $\mathrm{A}$ & -0.009 & 0.946 & 0.288 & 0.052 & -0.282 & 0.054 \\
\hline Trail Making test, $\mathrm{B}$ & -0.186 & 0.181 & -0.196 & 0.86 & -0.118 & 0.423 \\
\hline Clock's drawing & -0.204 & 0.207 & -0.071 & 0.680 & 0.295 & 0.091 \\
\hline NPI & -0.246 & 0.089 & -0.190 & 0.217 & -0.030 & 0.848 \\
\hline FBI, A & -0.104 & 0.487 & -0.187 & 0.236 & 0.123 & 0.449 \\
\hline FBI, B & -0.283 & 0.054 & -0.203 & 0.197 & 0.082 & 0.615 \\
\hline FBI, AB & -0.223 & 0.133 & -0.261 & 0.095 & 0.112 & 0.492 \\
\hline
\end{tabular}

CSF: Cerebrospinal fluid; MMSE: Mini-Mental State Examination; NPI: Neuropsychiatry Inventory; FBI: Frontal Behavioral Inventory. $p<0.05$ are highlighted. 


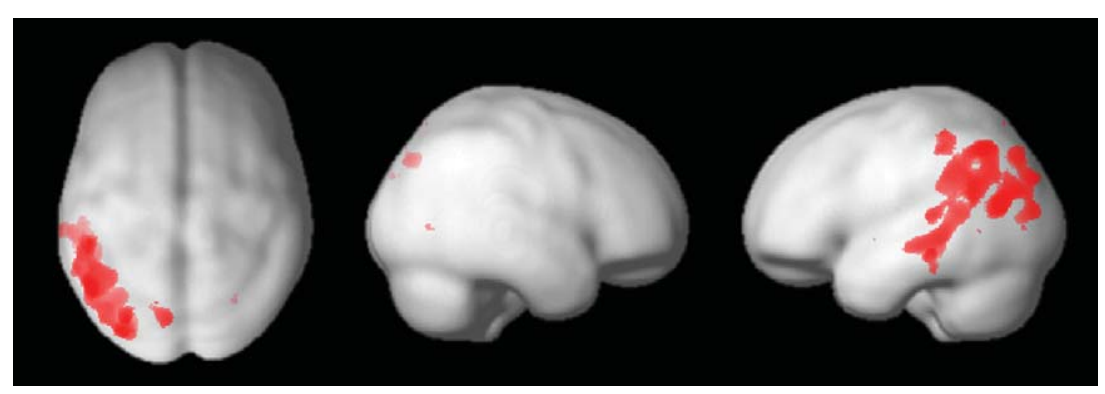

Fig. 1. Correlation analysis of CSF total Tau on grey matter atrophy $(p<0.001)$. See Table 3 for coordinates.

Table 3

Location of the peaks of cerebral brain atrophy in FTLD patients associated with CSF tau levels

\begin{tabular}{lcccccr}
\hline Region & $x$ & $y$ & $z$ & $T$ & $p$ & Cluster size \\
\hline L middle temporal gyrus & -67 & -33 & -13 & 4.210 & $<0.001$ & 320 \\
L middle temporal gyrus & -36 & -70 & 17 & 7.800 & $<0.001$ & 16223 \\
L inferior parietal lobule & -53 & -39 & 46 & 4.730 & $<0.001$ & 475 \\
\hline
\end{tabular}

L: Left.

cally associated with greater atrophy in language areas, namely left middle temporal gyrus and left inferior parietal lobule.

The inverse association, i.e., the lower the CSF tau the greater the atrophy, did not show any voxel above the pre-established threshold.

In the same manner, even if with less voxel extent, CSF phospho-tau levels correlated with cortical atrophy in left inferior parietal lobule $(x, y, z=-54,-38,56$; $p<0.001)$ and superior temporal gyrus $(-49,-11,1$; $p<0.001$ ).

No significant association between $A \beta$ and brain atrophy as measured by magnetic resonance imaging was detected at the pre-established threshold.

\section{Survival analysis}

Out of 55 patients, 10 had been institutionalized or died throughout the 5-year observation. The median survival time from the onset of symptoms was 4.5 years $( \pm 2.6)$. Median values of CSF markers were considered for Cox proportional estimates using time at study enrollment/diagnosis. Compared to low CSF tau dosage $(<400 \mathrm{pg} / \mathrm{ml})$, high tau dosage group $(>400 \mathrm{pg} / \mathrm{ml}$ ) had an increased risk of mortality/early institutionalization $(\mathrm{HR}=4.73,95 \% \mathrm{CI}=1.15-19.3$, $p=0.031$ ).

Figure 2 displays the corresponding Kaplan Meier survival curves.

CSF phospho-tau and CSF A $\beta$ did not significantly correlate with rate of survival when this was calculated from time of disease onset. Age at onset of symptoms, gender, years of schooling, positive family history for

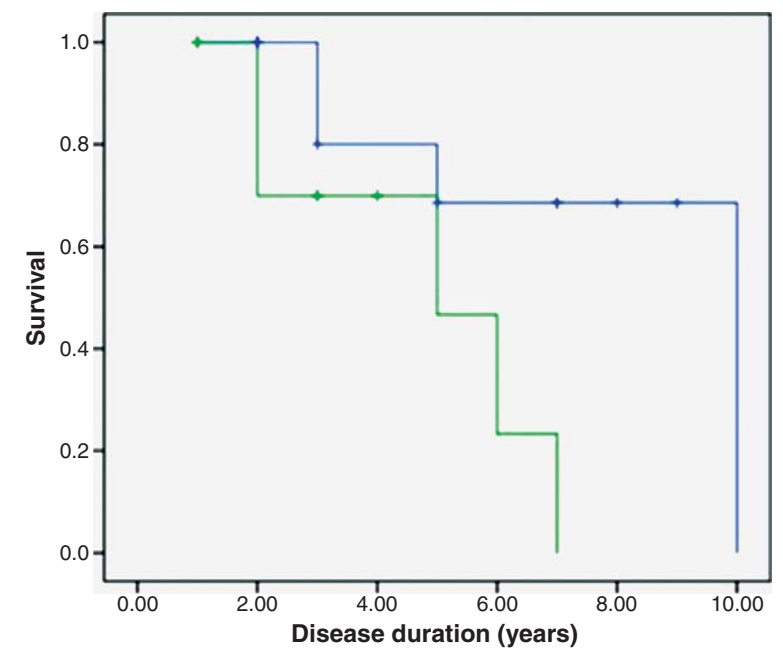

Fig. 2. Survival curves of FTLD groups defined by high versus low CSF tau levels. Kaplan Maier curves according to low CSF tau (blue) and high CSF tau (green) in FTLD patients $(p=0.031)$.

dementia, and comorbidities also did not significantly correlate with rate of survival.

\section{DISCUSSION}

In the present study, we showed that CSF total tau levels are associated with a specific clinical phenotype within the FTLD spectrum, namely characterized by greater language impairment. This was corroborated by neuroimaging data, and a significant correlation between CSF tau levels and grey matter atrophy in the left posterior temporal and inferior parietal lobes was 
reported. Finally, CSF tau levels were also associated with poor outcomes over time.

Tau is a microtubule-associated protein primarily localized in neuronal cells. In damaged brain, tau is released into the CSF from the neuronal cytoplasm, and it has been established that the concentration of CSF tau can reflect the degree of neuronal abnormalities in central nervous system disorders, such as Alzheimer's disease, Creutzfeldt-Jakob disease, encephalitis, Guillain-Barre syndrome, stroke, and active multiple sclerosis [13-17,34,35].

In FTLD, reports of CSF tau levels have been widely variable [6-8], but the meaning of such a finding needs to be further elucidated. The results of the present work suggest that CSF tau might be considered a marker of neurodegeneration, and higher levels of tau protein in CSF might be associated with increased vulnerability of specific brain areas, thus leading to defined neuropsychological deficits and brain atrophy pattern as compared to patients with lower CSF tau.

Language comprehension impairment is characteristically present in patients with $\mathrm{SD}$, but it might be detected even in the other clinical phenotypes, at onset or during disease course. Language deficits are disabling both for patients and carers, and this clinical feature is still unpredictable across the FTLD spectrum. In our series, we sought independent validation in living patients by evaluating the correlation between this biomarker and the pattern of cortical atrophy. We found that the higher the CSF tau levels, the greater the atrophy in left posterior temporal lobe and, with less extent, in left inferior parietal lobule. Imaging data cannot substitute histopathological evidence, but these results argue that CSF tau is significantly related to another marker that is often taken to reflect the underlying disease process [5], and this is in agreement with neuropsychological findings of a specific involvement of language functions.

The results herein reported might be related to the topographical distribution of CSF protein concentrations during the disease process, with higher CSF tau values related to degeneration involving cortical areas not remote from ventricular and lumbar spaces [4]. Accordingly, previous work has demonstrated that levels of CSF tau were specifically associated with greater left temporal cortical atrophy in FTLD [5]. However, the selective involvement of left cortical temporal areas related to high CSF tau should be matter of future evaluations, as a proper answer should be still searched out.

Our series must be interpreted with caution because the lack of histopathological diagnosis. Nevertheless, the results of CSF total tau in autopsy-proven patients with FTLD have been inconsistent [7]. One autopsy study reported significantly increased CSF tau compared to normal controls [36], while another study showed CSF tau within normal range [37]. The major limitation of the above works is the small sample size and the lack of a careful evaluation of the pathological FTLD spectrum, with varying number of patients with Pick's disease, FTLD tau-positive, or FTLD 43-kDa transactivation-responsive DNA-binding protein (TDP43)-positive disorders.

Indeed, low CSF tau levels might be associated to either FTLD tau-negative or to FTLD tau-positive pathology with the possibility that tau is sequestered into the brain in the form of filamentous inclusions or Pick's bodies [5]. In the same view, high CSF tau might be related either to FTLD tau-positive or to a more aggressive disease independent of neuropathology, as tau is an aspecific marker of axonal damage.

Moreover, CSF tau levels seem to be quite specific as compared to phospho-tau and $A \beta$, which led to less significant findings. In fact, CSF tau reflects the intensity of neuronal degeneration [13-17,34], while phospho-tau mirrors the hyperphosphorylation of tau with subsequent formation of tangles [38], and $A \beta$ is the marker of deposition of amyloid into plaques $[39,40]$. Accordingly, in our clinical series, that likely included both FTLD tau-positive and FTLD tau-negative cases, a marker of tangles formation as well as a marker of Alzheimer's disease cannot be of help. In particular, in the present series, we carefully excluded patients with low $A \beta$ levels, as suggestive of ongoing Alzheimer's disease pathology, to avoid possible misdiagnoses and confounds. Moreover, in regard to phospho-tau evaluation, we considered tau phosphorylated in P181 which is mainly typical of Alzheimer's disease profile, thus might being less sensitive to FTLD pathology.

CSF tau was not only a marker of clinical phenotype but was also associated with worse prognosis over time. The association between CSF tau and poor outcome might be due to a greater aggressiveness of the disease, with higher values of the neurodegeneration marker, or to the specific involvement of language function that would lead to an earlier institutionalization.

Several caveats should be kept in mind when interpreting our results. Neuropathological data are missing; furthermore, a large sample size and confirmation studies are warranted.

In conclusion, we suggest that biomarkers might be used not only as diagnostic tools across neurodegenerative disorders, but as markers of clinical phenotype 
and prognosis. CSF tau levels might be considered in clinical grounds and in future pharmacological trials to define FTLD with poor outcome. Association studies between CSF markers and autopsy proven cases are mandatory.

\section{ACKNOWLEDGMENTS}

The authors are indebted with Drs Chiara Agosti and Antonella Alberici for clinical assistance and to Ms Elisa Greotti for valuable technical support. The work was supported by grants of MIUR $60 \%$ to B.B. and A.P., and "Centre for Behavioural Disturbances and Neurodegenerative Disease, EULO” to A.P.

Authors' disclosures available online (http://www. j-alz.com/disclosures/view.php?id=647).

\section{REFERENCES}

[1] Neary D, Snowden JS, Gustafson LU, Stuss D, Black S, Freedman M, Kertesz A, Robert PH, Albert M, Boone K, Miller BL, Cummings J, Benson DF (1998) Frontotemporal lobar degeneration: a consensus on clinical diagnostic criteria. Neurology 51, 1546-1554.

[2] Borroni B, Alberici A, Grassi M, Turla M, Zanetti O, Bianchetti A, Dalla Volta G, Rozzini R, Gilberti N, Bellelli G, Padovani A (2010) Is frontotemporal lobar degeneration a rare disorder? Evidence from a preliminary study in Brescia county, Italy. J Alzheimers Dis 19, 111-116.

[3] Borroni B, Brambati SM, Agosti C, Gipponi S, Bellelli G, Gasparotti R, Garibotto V, Di LM, Scifo P, Perani D, Padovani A (2007) Evidence of white matter changes on diffusion tensor imaging in frontotemporal dementia. Arch Neurol 64, 246-251.

[4] Riemenschneider M, Wagenpfeil S, Diehl J, Lautenschlager N, Theml T, Heldmann B, Drzezga A, Jahn T, Forstl H, Kurz A (2002) Tau and Abeta42 protein in CSF of patients with frontotemporal degeneration. Neurology 11, 1622-1628.

[5] Grossman M, Farmer J, Leight S, Work M, Moore P, Van DV, Pratico D, Clark CM, Coslett HB, Chatterjee A, Gee J, Trojanowski JQ, Lee VM (2005) Cerebrospinal fluid profile in frontotemporal dementia and Alzheimer's disease. Ann Neurol 57, 721-729.

[6] Borroni B, Alberici A, Archetti S, Magnani E, Di LM, Padovani A (2010) New insights into biological markers of frontotemporal lobar degeneration spectrum. Curr Med Chem 17, 1002-1009.

[7] Bian H, Van Swieten JC, Leight S, Massimo L, Wood E, Forman M, Moore P, de KI, Clark CM, Rosso S, Trojanowski J, Lee VM, Grossman M (2008) CSF biomarkers in frontotemporal lobar degeneration with known pathology. Neurology $\mathbf{6}$, 1827-1835.

[8] Pijnenburg YA, Schoonenboom SN, Barkhof F, Knol DL, Mulder C, Van Kamp GJ, van Swieten JC, Scheltens P (2006) CSF biomarkers in frontotemporal lobar degeneration: relations with clinical characteristics, apolipoprotein E genotype, and neuroimaging. J Neurol Neurosurg Psychiatry 77, 246248.

[9] Mattsson N, Zetterberg H, Hansson O, Andreasen N, Parnetti L, Jonsson M, Herukka SK, van der Flier WM, Blankenstein
MA, Ewers M, Rich K, Kaiser E, Verbeek M, Tsolaki M, Mulugeta E, Rosen E, Aarsland D, Visser PJ, Schroder J, Marcusson J, de LM, Hampel H, Scheltens P, Pirttila T, Wallin A, Jonhagen ME, Minthon L, Winblad B, Blennow $\mathrm{K}$ (2009) CSF biomarkers and incipient Alzheimer disease in patients with mild cognitive impairment. JAMA 22, 385-393.

[10] Visser PJ, Verhey F, Knol DL, Scheltens P, Wahlund LO, Freund-Levi Y, Tsolaki M, Minthon L, Wallin AK, Hampel H, Burger K, Pirttila T, Soininen H, Rikkert MO, Verbeek MM, Spiru L, Blennow K (2009) Prevalence and prognostic value of CSF markers of Alzheimer's disease pathology in patients with subjective cognitive impairment or mild cognitive impairment in the DESCRIPA study: a prospective cohort study. Lancet Neurol 8, 619-627.

[11] Dubois B, Feldman HH, Jacova C, Dekosky ST, BarbergerGateau P, Cummings J, Delacourte A, Galasko D, Gauthier S, Jicha G, Meguro K, O’brien J, Pasquier F, Robert P, Rossor M, Salloway S, Stern Y, Visser PJ, Scheltens P (2007) Research criteria for the diagnosis of Alzheimer's disease: revising the NINCDS-ADRDA criteria. Lancet Neurol 6, 734-746.

[12] Borroni B, Di Luca M, Padovani A (2006) Tau haplotype affects CSF Tau levels in frontotemporal dementia: implication for diagnostic purposes. J Neurol 253, 946.

[13] Van EB, Quoilin S, Boons J, Martin JJ, Cras P (2003) A prospective study of CSF markers in 250 patients with possible Creutzfeldt-Jakob disease. J Neurol Neurosurg Psychiatry 74, 1210-1214.

[14] Brettschneider J, Petzold A, Sussmuth SD, Ludolph AC, Tumani H (2006) Axonal damage markers in cerebrospinal fluid are increased in ALS. Neurology 28, 852-856.

[15] Teunissen CE, Dijkstra C, Polman C (2005) Biological markers in CSF and blood for axonal degeneration in multiple sclerosis. Lancet Neurol 4, 32-41.

[16] Jin K, Takeda A, Shiga Y, Ohnuma A, Nomura H, Arai H, Kusunoki S, Ikeda M, Itoyama Y (2006) CSF tau protein: a new prognostic marker for Guillain-Barre syndrome. Neurology 24, 1470-1472.

[17] Ost M, Nylen K, Csajbok L, Ohrfelt AO, Tullberg M, Wikkelso C, Nellgard P, Rosengren L, Blennow K, Nellgard B (2006) Initial CSF total tau correlates with 1-year outcome in patients with traumatic brain injury. Neurology $\mathbf{1 4}$, 1600-1604.

[18] Ashburner J, Friston KJ (2000) Voxel-based morphometrythe methods. Neuroimage 11, 805-821.

[19] Ashburner J, Friston KJ (2001) Why voxel-based morphometry should be used. Neuroimage 14, 1238-1243.

[20] Folstein MF, Folstein SE, McHugh PR (1975) "Mini-mental state". A practical method for grading the cognitive state of patients for the clinician. J Psychiatr Res 12, 189-198.

[21] Borroni B, Agosti C, Premi E, Cerini C, Cosseddu M, Paghera B, Bellelli G, Padovani A (2009) The FTLD-modified Clinical Dementia Rating scale is a reliable tool for defining disease severity in Frontotemporal Lobar Degeneration: evidence from a brain SPECT study. Eur J Neurol 17, 703707.

[22] Babcock MA, Levy L (1940) The measurement of mental efficiency of mental functioning (revised examination). Test and Manual of Directions. CH Stoelting: Chicago.

[23] Bingham WC, Burke HR, Murray S (1966) Raven's progressive matrices: construct validity. J Psychol 62, 205-209.

[24] Loring DW, Martin RC, Meador KJ, Lee GP (1990) Psychometric construction of the Rey-Osterrieth Complex Figure: methodological considerations and interrater reliability. Arch Clin Neuropsychol 5, 1-14. 
[25] Isaacs B, Kennie AT (1973) The Set test as an aid to the detection of dementia in old people. Br J Psychiatry 123, 467-470.

[26] Blackburn Hl, Benton Al (1973) Revised administration and scoring of the digit span test. J Consult Psychol 21, 139-143.

[27] De Renzi, Vignolo La (1962) The token test: a sensitive test to detect receptive disturbances in aphasics. Brain 85, 665-678.

[28] Reitan RM (1955) The relation of the trail making test to organic brain damage. J Consult Psychol 19, 393-394.

[29] Sunderland T, Hill JL, Mellow AM, Lawlor BA, Gundersheimer J, Newhouse PA, Grafman JH (1989) Clock drawing in Alzheimer's disease. A novel measure of dementia severity. J Am Geriatr Soc 37, 725-729.

[30] De Renzi, Motti F, Nichelli P (1980) Imitating gestures. A quantitative approach to ideomotor apraxia. Arch Neurol 37, 6-10.

[31] Cummings JL, Mega M, Gray K, Rosenberg-Thompson S, Carusi DA, Gornbein J (1980) The Neuropsychiatric Inventory: comprehensive assessment of psychopathology in dementia. Neurology 44, 2308-2314.

[32] Kertesz A, Nadkarni N, Davidson W, Thomas AW (2000) The Frontal Behavioral Inventory in the differential diagnosis of frontotemporal dementia. J Int Neuropsychol Soc 6, 460-468.

[33] Good CD, Scahill RI, Fox NC, Ashburner J, Friston KJ, Chan D, Crum WR, Rossor MN, Frackowiak RS (2000) Automatic differentiation of anatomical patterns in the human brain: validation with studies of degenerative dementias. Neuroimage 17, 29-46.

[34] Blennow K (2004) Cerebrospinal fluid protein biomarkers for Alzheimer's disease. NeuroRx 1, 213-225.
[35] Hesse C, Rosengren L, Vanmechelen E, Vanderstichele H, Jensen C, Davidsson P, Blennow K (2000) Cerebrospinal fluid markers for Alzheimer's disease evaluated after acute ischemic stroke. J Alzheimers Dis 2, 199-206.

[36] Arai H, Morikawa Y, Higuchi M, Matsui T, Clark CM, Miura M, Machida N, Lee VM, Trojanowski JQ, Sasaki H (1997) Cerebrospinal fluid tau levels in neurodegenerative diseases with distinct tau-related pathology. Biochem Biophys Res Commun 18, 262-264.

[37] Clark CM, Xie S, Chittams J, Ewbank D, Peskind E, Galasko D, Morris JC, McKeel DW Jr, Farlow M, Weitlauf SL, Quinn J, Kaye J, Knopman D, Arai H, Doody RS, DeCarli C, Leight S, Lee VM, Trojanowski JQ (2003) Cerebrospinal fluid tau and beta-amyloid: how well do these biomarkers reflect autopsyconfirmed dementia diagnoses? Arch Neurol 60, 16961702.

[38] Buerger K, Ewers M, Pirttila T, Zinkowski R, Alafuzoff I, Teipel SJ, DeBernardis J, Kerkman D, McCulloch C, Soininen H, Hampel H (2006) CSF phosphorylated tau protein correlates with neocortical neurofibrillary pathology in Alzheimer's disease. Brain 129, 3035-3041.

[39] Fagan AM, Mintun MA, Mach RH, Lee SY, Dence CS, Shah AR, LaRossa GN, Spinner ML, Klunk WE, Mathis CA, Dekosky ST, Morris JC, Holtzman DM (2006) Inverse relation between in vivo amyloid imaging load and cerebrospinal fluid Abeta42 in humans. Ann Neurol 59, 512-519.

[40] Strozyk D, Blennow K, White LR, Launer LJ (2003) CSF Abeta42 levels correlate with amyloid-neuropathology in a population-based autopsy study. Neurology $\mathbf{2 5}$, 652-656. 